\title{
Partidos políticos y democracia (A propósito de Esencia y valor de la democracia de Hans Kelsen)
}

\author{
Luis Armando González¹
}

Recibido en septiembre de 2014, aceptado en noviembre de 2014

A Judith Maza

"Pero la plaga del engreimiento -es engreimiento y soberbia enmendarles la plana a los muertos, tachar lo que otros escribieron, modificar y falsear los hechos para adecuarlos a nuestro gusto-va mucho más lejos, y alcanza cotas ilusas para mí casi inconcebibles".

Javier Marías, Tiempos ridículos. Madrid: Alfaguara, 2013, p. 33.

\begin{abstract}
Resumen
Luis Armando González presenta un rico análisis del libro Esencia y valor de la democracia, de Hans Kelsen. El libro, publicado en 1920, responde a las críticas de su tiempo a la democracia partidaria: crítica la 'antipolítica', el 'antipartidismo' y el 'antiparlamentarismo'. Partiendo de las tesis principales de Kelsen, el autor pone en relieve la defensa de las praxis democráticas a partir de la crítica a sus detractores.
\end{abstract}

Palabras claves:

Antipolítica, antiparlamentarismo, Hans Kelsen, democracia.

\begin{abstract}
Luis Armando González presents a dense analysis of the book "The Essence and Value of Democracy", by Hans Kelsen. The book, published in 1920, addresses the critiques of "party democracy" of that time: 'anti-politics', 'anti-political parties', and 'anti-parliamentary'. Primarily based on Kelsen's theses, this article highlights the defense of democratic praxis from the critique of its detractors.
\end{abstract}

Keywords:

Culture, modernity, postmodernity, globalization, intercultural, transcultural identity, difference, plurality.

1. Luis Armando González, Escuela Superior de Maestros, Ministerio de Educación, San Salvador, armando.gonzalez@mined.gob.sv 


\section{Introducción}

La antipolítica -el rechazo acerbo a la política, por considerarla espacio de bajezas e inmoralidad - tiene dos frentes de ataque: los partidos políticos y los parlamentos (o las Asambleas Legislativas). Cualquiera pensaría, a juzgar por las arremetidas recientes por parte de algunos sectores mediáticos y analistas de derecha, que la antipolítica es algo reciente, pero no: tiene un largo antecedente que se puede rastrear hasta las primeras dos décadas del siglo XX. En efecto, en los años 20, vio la luz el libro de Hans Kelsen (1881-1973) Esencia y valor de la democracia (1920), en el cual este autor plantea una interesante crítica al antipartidismo y antiparlamentismo vigentes en esa época.

Antes de reseñar las tesis básicas de ese texto, conviene llamar la atención acerca de la descalificación que pudieran hacer algunos "kelsenianos" u otros "estudiosos" de las ideas políticas en el sentido de ubicar ese libro de Kelsen en un momento de su trayectoria de "menor madurez", lo cual restaría peso a sus tesis.

Desde el siglo XX se establecieron, de parte de algunos estudiosos, criterios de división en las trayectorias y obras de determinados autores. Dos de estos autores se pueden citar como ejemplos: Karl Marx y Ludwig Wittgenstein. En el caso del primero, se estableció -gracias a Louis Althusser- la distinción entre el "joven Marx" y el "viejo Marx". En el caso del segundo, algunos especialistas en filosofía del lenguaje establecieron la distinción entre el "primer Wittgenstein" y el "segundo Wittgenstein".

Quienes procedieron a esta división (tanto en Marx como en Wittgenstein) tenían en lo esencial dos motivos: Althusser quería privilegiar al "Marx maduro" o "científico", en contraposición al "Marx joven" o "humanista" (no científico). Este esfuerzo pronto se vio cuestionado desde distintos flancos, por su arbitrariedad y poco sostén teórico-filosófico: muchos de los motivos del Marx joven se concretaban en el Marx viejo, siendo evidente una continuidad en la obra del filósofo alemán. Era insostenible, pues, privilegiar una parte de la obra y trayectoria de Marx en detrimento de la otra (considerada inferior e incluso descartable). Lo único que esa decisión reflejaba eran los prejuicios e intereses ideológico-políticos del propio Althusser, y no una debilidad de la obra juvenil de Marx, rica en elaboraciones teóricas y filosóficas.

En el otro ejemplo, la separación entre el "primer" y "segundo" Wittgenstein tenía que ver con las diferencias sustantivas existentes entre el Tractatus logico-philosophicus (1922) y el Cuaderno azul y marrón (1933-1935) y las Investigaciones filosóficas (1953). Si la primera obra constituye un aporte fundamental al positivismo lógico, las segundas sitúan a su autor en el horizonte de los "juegos del lenguaje". Aunque entre quienes defendieron la tesis de los dos Wittgenstein no dejaba de estar presente la tentación de destacar la 
"superioridad" del "segundo" sobre el "primero", lo más relevante era marcar un trazo analítico entre los aportes filosóficos de una y otra etapa. También aquí, con el paso del tiempo, ha dejado de aceptarse esa pretendida superioridad: en ambos momentos, Wittgenstein dejó su marca en la historia de la filosofía, en particular en la filosofía del lenguaje. Y para comprender esa historia en el siglo XX es inevitable estudiar a los dos Wittgenstein.

En fin, la práctica de deslegitimar una determinada obra o conjunto de obras porque se ubican en una fase "temprana" en la trayectoria de un autor (o, lo que es menos frecuente, porque se ubica en una atapa "madura"), no goza de mayor aceptación en la actualidad. Ni siquiera cuando el propio autor la descalifica o reniega de ella, una obra pierde valor o importancia. Viene a cuento, aquí, el caso de Franz Kafka quien dejó, como última voluntad, la orden de destruir sus manuscritos, lo cual obviamente no se hizo. Sin el menor reparo de la crítica, esas obras se consideran suyas, pese a su oposición a que se conocieran.

Y es que, en definitiva, lo que da valor e importancia a una obra es su pertinencia para ayudar a entender problemas actuales (y la actualidad de una obra es distinta en cada situación histórica) o porque abre vías de reflexión (o de investigación) novedosas. Es decir, no es legítimo desde visiones académicas serias, restar valor o importancia al aporte de un autor sólo porque se considera que esa contribución es de una etapa temprana de su evolución intelectual. Después de todo, en el plano intelectual, es arbitrario establecer criterios de "etapa temprana" o "madura". Lo que tal pretensión oculta es el interés de algunos "estudiosos" (o simples comentaristas) posteriores por excluir de un autor aquello que no les satisface. Pero no hay razones de peso para esa mutilación. No hay razones de peso que avalen la priorización de una obra sobre otra, considerándola mejor o la plena expresión de lo que un autor dijo o quiso decir sobre tal o cual asunto.

Es un abuso proceder a tales mutilaciones. Es engreimiento y soberbia. $Y$ es que una obra -un texto-sólo está respaldado por su propia consistencia (o inconsistencia) interna y por su pertinencia y actualidad. No puede ser descartado o minusvalorado (o sobrevalorado) por su ubicación en la trayectoria personal de su autor. Vale lo que vale por lo que dice o no dice a sus lectores en cada situación histórica concreta.

\section{Esencia y valor de la democracia: tesis principales}

Dicho lo anterior, el libro Esencia y valor de la democracia es una obra de Hans Kelsen igual de legítima que cualquiera que sus otras obras, no importa lo que dijera el mismo sobre ello o lo que digan (o puedan decir) comentaristas de segunda o tercera categoría. Lo que importa de este libro son sus ideas sobre los partidos políticos y el parlamento. No son ideas mejores o peores que otras que él mismo haya sostenido antes o después; son simplemente las 
44 Partidos políticos y democracia. A propósito de Esencia y valor de la democracia de Hans kelsen. Luis Armando González

ideas que plasmó en ese escrito en particular, es cierto que en un momento histórico determinado), pero que trascienden esa época: son pertinentes y actuales en unas circunstancias en las cuales hay un clima antipartidos y antiparlamento ciertamente preocupante. Bien visto, lo que hace interesantes las ideas planteadas en Esencia y valor de la democracia no es que las planteara Kelsen -una idea no es interesante porque la exponga tal o cual autor: hay ideas absurdas propuestas por autores respetables- sino que son pertinentes y actuales.

\subsection{Participación política}

Uno de los problemas centrales abordados en este texto es de la participación política de los ciudadanos en una democracia. O, como dice Kelsen, la participación del individuo en la formación de la voluntad colectiva, que es el contenido de los derechos políticos. Se trata, nos dice, de una parte de la vida de las personas, no de toda su vida:

"el hombre nunca pertenece en su totalidad, o sea en todas sus funciones y actividades espirituales y físicas, a la colectividad social, ni siquiera al Estado, que es quien más puede absorberle, y mucho menos a un Estado cuya forma se inspire en el ideal de la libertad. Siempre son solamente muy determinadas las manifestaciones del individuo afectadas por la ordenación política, y siempre ha de quedar fuera de ésta una parte más o menos grande la vida humana, permaneciendo, por consiguiente, exenta del Estado una determinada esfera del individuo". ${ }^{2}$

No puede aceptarse, en un Estado inspirado en el ideal de libertad, una supuesta “pertenencia” del individuo al Estado, pues existe -y debe reivindicarse- una esfera del individuo exenta del Estado: su vida privada. Y esa vida privada, que es "una parte más o menos grande de la vida humana", no puede ser constreñida por nada ni nadie apelando a condicionamientos laborales (ser, por ejemplo, empleado estatal) o de otro tipo.

Dicho lo anterior, es innegable que una de las claves de la democracia es la participación de los individuos en la formación de la voluntad colectiva, participación en la cual -como ya se dijo- se concretan sus derechos políticos. El término "pueblo" identifica -dice Kelsen- a los titulares de esos derechos políticos, pero el pueblo "representa, aun en una democracia radical, sólo un pequeño sector de la totalidad de los sometidos a la ordenación política, o sea el pueblo como objeto de poder. Ciertos límites naturales, como la edad, la capacidad mental y moral, se oponen a la generalización de los derechos políticos y restringen al pueblo en el sentido activo, en tanto que para el sentido pasivo no existe restricción alguna" (p. 33). No todo el pueblo, pues, está llamado a 
participar en la formación de la voluntad colectiva en una democracia; sí, todo el pueblo está sometido al ordenamiento político establecido. "Es característico -añade nuestro autor - que en la ideología democrática quepan las mayores restricciones del pueblo como conjunto de los partícipes del poder". ${ }^{3}$

De hecho, la concreción histórica de la ideología democrática ha exigido vencer muchas de esas restricciones, de tal suerte que el papel del pueblo como "partícipe del poder" sea cada vez más amplio. Diversas medidas y fórmulas se han elaborado y puesto en práctica en distintos momentos y situaciones: inclusión política de las mujeres (lo cual supuso una importante conquista democrática), eliminación de requisitos sociales y económicos, reducción del límite de edad para ser el ejercicio de los derechos políticos, introducción de mecanismos de consulta popular como referéndums y plebiscitos, etc. Cada país ha diseñado los esquemas de ampliación de la participación política del demos más convenientes para su propia realidad, con lo cual la democracia se ha enriquecido y profundizado.

\title{
2.2. Partidos políticos y democracia
}

Sin embargo, hay una restricción que no se ha podido vencer y que es sumamente difícil que se venza en las sociedades contemporáneas: el ejercicio directo del poder por todo el demos o por la mayor parte de sus miembros. Hay limitaciones prácticas para que ello sea viable de manera permanente, sin que tales limitaciones impidan la puesta en práctica de mecanismos temporales de participación directa del pueblo en el ejercicio del poder. Esto fue visto por Kelsen en los años 20 y 30 del siglo XX, lo cual le permitió reivindicar la idea de la representación política y la importancia de los partidos políticos en la democracia.

\begin{abstract}
"Dentro de la masa de aquellos que ejerciendo efectivamente sus derechos políticos toman parte en la formación de la voluntad del Estado, habría que distinguir entre los que sin opinión ni criterio propios obedecen a la influencia de otros, y los pocos que por su propia iniciativa -en armonía con la idea de democracia- imprimen una dirección al proceso de la formación de la voluntad colectiva. Semejante investigación conduce al descubrimiento de la virtualidad de uno de los elementos más destacados de la democracia real: los partidos políticos". ${ }^{4}$
\end{abstract}

En un contexto de un fuerte antipartidismo, como lo fue la Alemania de los años 20 y 30 , no dudó en afirmar que brota de los partidos políticos "una parte muy esencial de la formación de la voluntad colectiva: la preparación decisiva para la dirección de aquella voluntad, proceso que, alimentado por los impulsos de

3. Ibíd., p. 33.

4. Ibíd., p. 35 
los partidos políticos y por muchas fuentes anónimas, sólo sale a la superficie en la Asamblea Nacional o Parlamento, donde encuentra su cauce regular" ( $p$. 35). Y con contundencia, afirma lo siguiente:

"la democracia moderna descansa, puede decirse, sobre los partidos políticos, cuya significación crece con el fortalecimiento progresivo del principio democrático. Dada esta realidad, son explicables las tendencias -si bien hasta ahora no muy vigorosas- a insertar los partidos políticos en la Constitución, conformándolas jurídicamente con lo que de hecho son ya hace tiempo: órganos para la formación de la voluntad estatal". 5

Se trata, según Kelsen, de un proceso de "racionalización del poder" que va aparejado con "la democratización del Estado moderno": los partidos políticos son “órganos constitucionales del Estado en especial”. El rechazo monárquico a los partidos no era sino "una enemistad mal disimulada contra la democracia"6. Y también contra los individuos, quienes aisladamente carecen "por completo de existencia política positiva por no poder ejercer ninguna influencia efectiva en la formación de la voluntad del Estado". ${ }^{7}$ Por consiguiente:

"la democracia sólo es posible cuando los individuos, a fin de lograr una actuación sobre la voluntad colectiva, se reúnen en organizaciones definidas por diversos fines políticos, de tal manera que entre el individuo y el Estado se interpongan aquellas colectividades que agrupan en forma de partidos políticos las voluntades políticas coincidentes de los individuos. Así no puede dudarse que el descrédito de los partidos políticos por parte de la teoría y la doctrina del derecho político de la monarquía constitucional encubría un ataque contra la realización de la democracia. Sólo por ofuscación o dolo puede sostenerse la posibilidad de la democracia sin partidos políticos. La democracia, necesaria e inevitablemente, requiere de un Estado de partidos". ${ }^{8}$

A más de algún denostador de los partidos no le caerá en gracia la tesis de Kelsen. Seguramente, argüirá que este autor era -en ese momento- demasiado ingenuo como para darse cuenta de la "maldad" de los partidos políticos. 0 en todo caso argumentará que entonces los partidos no eran lo que son ahora, cuando su "perversión" es extrema. Es indudable que desde los años 20 del siglo XX hasta la época actual los partidos políticos han cambiado y acumulado (y dado lugar a) experiencias positivas y negativas. Ha habido partidos ( $y$ políticos) francamente detestables y truculentos. Pero los ha habido también

\footnotetext{
5. Ibíd., p. 36

6. Ibíd.

7. Ibíd., pp. 36-37

8. Ibíd.
} 
comprometidos con el bien público y éticamente honorables.

Una cosa es cierta: quienes en la actualidad ven en los partidos políticos "maldad", "corrupción" o "bajeza" no se distinguen de quienes opinaban lo mismo en la época de Kelsen. Es decir, en tiempos de Kelsen había quienes pensaban que los partidos políticos eran expresión de la peor perversión ética y política, igual a como piensan, en nuestro tiempo, muchos de los defensores del antipartidismo. Parece ser que a unos y otros les importa poco el quehacer real de los partidos, pues lo suyo era y es un antipartidismo a priori: los partidos políticos son malos, perversos y bajos por ser lo que son, porque ello es intrínseco a su naturaleza. Y esto se sostiene a priori, sin atender a la diversidad, desempeño real y evolución de los partidos políticos.

Es precisamente la realidad efectiva de los partidos (en una democracia) lo que le interesa a Kelsen. $Y$ es eso lo que debe preocupar en la actualidad a los estudiosos de los partidos, no los prejuicios acerca de su intrínseca maldad y corrupción. Esos prejuicios, que se amparan en tesis como las que sostienen que "todos los partidos son corruptos", "todos los partidos abusan del poder" o todos los partidos están formados por camarillas mediocres que se aprovechan de los recursos de la sociedad", son además de analíticamente perniciosos -no permiten entender el rol de los partidos ni la diversidad de prácticas políticas que éstos encauzan- sumamente antidemocráticos, pues suelen estar orientados a desacreditar a instancias de intermediación sociopolítica imprescindibles en las democracias contemporáneas.

\subsection{Debilidades del antipartidismo}

En tiempos de Kelsen -al igual que en la actualidad-, uno de los frentes de ataque de los críticos de los partidos era el "egoísmo" de estos últimos, el cual los lleva a defender intereses de grupo y no el "bien común" que es precisamente lo que -según esos críticos- corresponde al Estado. Kelsen les respondió que "los Estados históricos representan casi siempre, bajo la aureola ideológica de que se rodea todo poder, organizaciones puestas al servicio de los intereses del grupo gobernante. Su pretensión de obrar como instrumentos del interés colectivo de una comunidad solidaria significaría en el mejor caso tomar el ideal por la realidad; pero, por regla general, no pasan de idealizar la realidad por motivos políticos" ". El Estado histórico no es ajeno a los intereses de grupo, sólo que tal cosa no se suele reconocer. Los partidos políticos no niegan -no deberían negar- los intereses que defienden, pues es partir de esos intereses que se expresa la heterogeneidad del pueblo y que, por tanto, obligan a la transacción de intereses divergentes.

Desde el punto de vista de Kelsen no se ve cómo otros grupos políticos puedan sustituir a los partidos como "factores de la formación de la voluntad del

9. Ibíd., p. 42 
Estado”. En una argumentación que podría ser usada hoy, Kelsen descalifica a los que creen que los "grupos profesionales" pueden ocupar el lugar de los partidos políticos, apelando a que tales grupos no tienen intereses, sino que son neutrales.

"Al tratar de la cuestión relativa a qué otros grupos políticos podrían sustituir a los partidos como factores de la formación de la voluntad del Estado, se demuestra lo infundado de esta argumentación contra los partidos políticos, siendo casi el único recurso conceder a los grupos profesionales la función que hoy desempeñan los partidos. El carácter interesado de estos grupos... no es inferior, sino probablemente más intenso todavía que el de los partidos políticos, puesto que en aquéllos sólo pueden mediar intereses materiales. La voluntad colectiva, dentro de la inevitable pugna de intereses acreditada por la experiencia, si no ha de ser la expresión unilateral de intereses de grupo, sólo puede consistir en la resultante o transacción de intereses divergentes, y la articulación del pueblo en partidos políticos significa propiamente la creación de condiciones orgánicas que hagan posible aquella transacción y permitan a la voluntad colectiva orientarse en una dirección equitativa". ${ }^{10}$

Casi 100 años no separan del momento en que tales ideas fueron publicadas. Pero parecen escritas para nosotros, cuando algunas gremiales empresariales (o agrupaciones profesionales auspiciadas por ellas) pretenden reemplazar a los partidos políticos como instancias de transacción y articulación de intereses divergentes. Y lo peor: eso se cobija bajo un manto democrático que en realidad no es tal, como no lo era en la época del Kelsen.

"La actitud adversa a la constitución de los partidos, y hostil, en el fondo a la democracia, sirve, consciente o inconscientemente, a las fuerzas políticas que tienden a la hegemonía de un solo grupo de intereses, que en la misma medida en que se niega a tomar en cuenta otro interés ajeno, procura disfrazarse ideológicamente como interés colectivo 'orgánico', 'verdadero' y 'comprensivo'”."11

Si se sustituye, en la primera línea del párrafo citado, la palabra "constitución" por la palabra "existencia", perfectamente se puede aplicar a la situación actual de El Salvador, en un momento en el cual el antipartidismo reinante está al servicio de "fuerzas políticas que tienden a la hegemonía de un solo grupo de intereses". En la época de Kelsen se quería negar el reconocimiento jurídico a los partidos, lo cual él califico de "ceguera ante la realidad". En la nuestra, se les quiere negar el derecho a existir, lo cual es también una ceguera ante la realidad.

10. Ibíd., pp. 42-43

11. Ibíd., pp. 43-44 


\begin{abstract}
"Un avance incontable conduce en todas las democracias a la división del pueblo en partidos políticos, o, mejor dicho, ya que preliminarmente no existía el 'pueblo' como potencia política, el desarrollo democrático induce a la masa de individuos aislados a organizarse en partidos políticos, y con ello despierta originariamente las fuerzas sociales que con alguna razón pueden designarse con el nombre de 'pueblo'. Si las Constituciones de las repúblicas democráticas -que en éste como en tantos puntos se hallan todavía bajo el influjo de la ideología de las monarquías constitucionales- niegan el reconocimiento jurídico a los partidos políticos, no es desde luego con la intención que perseguían aquéllas, o sea la obstrucción de la democracia, sino por ceguera ante la realidad". ${ }^{12}$
\end{abstract}

\title{
2.4. Parlamentarismo y democracia
}

Y esa ceguera ante la realidad es la conduce no sólo a no reconocer la necesidad de los partidos en un régimen democrático, sino a no querer entender que la democracia moderna es una "democracia parlamentaria", "en la cual la voluntad colectiva que prevalece es la determinada por la mayoría de aquellos que han sido elegidos por la mayoría de los ciudadanos"13. Es en el parlamentarismo (y en los parlamentos) en donde descansa fundamentalmente la democracia. Hubo quienes en tiempos de Kelsen -lo mismo que sucede ahora- pedían "con fervor la dictadura o un orden de representaciones profesionales" en reemplazo del parlamento. "No nos engañemos sobre ello: se padece hoy de cierta fatiga producida por el parlamentarismo, si bien o cabe hablar -como hacen algunos autores- de una crisis, una ‘bancarrota' o una 'agonía' del parlamentarismo”"14.

Contra quienes proclaman esa "bancarrota" y esa "agonía", Kelsen sostiene lo siguiente: "aunque la democracia y el parlamentarismo no son idénticos, no cabe dudar en serio - puesto que la democracia directa no es posible en Estado moderno- que el parlamentarismo es la única forma real en que puede plasmar la idea de la democracia dentro de la realidad social presente. Por ello, el fallo sobre el parlamentarismo es el fallo sobre la democracia"15. 0 dicho de otra manera: en las sociedades modernas, el parlamentarismo realiza la democracia; y, en ese sentido, ir en contra del parlamentarismo es ir en contra de la democracia. ¿Y por qué es tan importante el parlamentarismo para "plasmar" el ideal democrático dentro de la realidad presente? Su definición lo aclara:

"El parlamentarismo significa: Formación de la voluntad decisiva del Estado mediante órgano colegiado elegido por el pueblo en virtud de

12. Ibíd., p. 45

13. Ibíd., p. 47

14. Ibíd., p. 49

15. Ibíd., p. 50 
un derecho de sufragio general e igual, o sea democrático, obrando a base del principio de mayoría". ${ }^{16}$

Ni el Poder Ejecutivo ni el Poder Judicial realizan la democracia. Es el parlamento quien la realiza, en virtud de su conformación por decisión libre e igualitaria de los ciudadanos. El parlamento expresa mejor que ninguna otra instancia estatal la "autodeterminación democrática", es decir, "la idea de la libertad", puesto que "la lucha por el parlamentarismo era la lucha por la libertad política. Este hecho se olvida hoy, con frecuencia, dirigiendo críticas muchas veces injustas, contra el parlamentarismo"17. Pero la autodeterminación democrática expresada en el parlamento es una restricción de la autodeterminación propiciada por la democracia directa.

\begin{abstract}
"De ello resulta que el parlamentarismo se presenta como transacción entre la exigenciademocráticade la libertadyel principio, imprescindible para todo progreso de la técnica social, de la distribución diferenciada del trabajo. Se ha tratado de ocultar la considerable restricción que experimenta el ideal democrático por el hecho de que la voluntad estatal sea formada no por el pueblo, sino por un Parlamento muy distinto del mismo, aunque elegido por él... En vista de lo complicado de las circunstancias sociales, no podía aceptarse la forma primitiva de la democracia directa, ya que era imposible renunciar a las ventajas de la división del trabajo. Cuando más grande es la colectividad política, tanto menos capaz se muestra el 'pueblo', como tal, de desenvolver la actividad creadora de la formación directa de la voluntad política, y tanto más obligado se ve -aunque sólo fuese por razones técnico sociales- a limitarse a crear y controlar el verdadero mecanismo que forma la voluntad política". ${ }^{18}$
\end{abstract}

Ese mecanismo es, precisamente, el parlamento. Las críticas que se le hacen pueden conducir a reformarlo, pero no a abolirlo. Es decir, "el intento de eliminar por completo el Parlamento de entre los órganos de un Estado moderno, no podrán prosperar en definitiva"19. Es posible reformarlo en varias direcciones siendo una de las más importantes la ampliación de la participación del pueblo en las funciones legislativas:

"no puede negarse que la reglamentación de muchas cuestiones tendría distinto aspecto si la decisión no incumbiese exclusivamente al Parlamento, sino que necesitase el refrendo del cuerpo electoral. No tratamos de discutir si tal apelación al pueblo implicaría una ventaja para la formación de la voluntad del Estado. Basta indicar solamente,

\footnotetext{
16. Ibíd.

17. Ibíd.

18. Ibíd., p. 52

19. Ibíd., p. 60
} 
ante el argumento de la exclusión del pueblo con que se combate el parlamentarismo, que la institución del referéndum admite y necesita mayor amplitud, manteniendo en lo fundamental el principio parlamentario". ${ }^{20}$

Además de la institución del plebiscito y del referéndum constitucional, Kelsen propone, entre otras reformas, la "llamada iniciativa popular", que facilita la injerencia del pueblo en la formación de la voluntad estatal, manteniendo el "principio parlamentario 21 " y la supresión de la "inmunidad", "invocada no respecto a los electores, sino ante las autoridades, especialmente las de orden judicial".22

Por último, Kelsen es sumamente duro con quienes "aspiran a más que una simple reforma del sistema parlamentario, y piden con espíritu conservador su sustitución por una organización profesional"23, a partir de la idea de que el pueblo y debe puede organizarse por profesiones para participar políticamente. Eso es imposible, pues una organización profesional sería incapaz de articular y expresar no sólo la diversidad e heterogeneidad de los diversos grupos profesionales, sino de la sociedad en su conjunto. "Ello demuestra lo vacuo e inaplicable de la fórmula con que el principio profesionista pretende superar el principio parlamentario democrático: Que cada grupo se reconozca en la formación de la voluntad estatal una participación proporcional a su importancia en el conjunto nacional". ${ }^{24} \mathrm{Y}$ remata nuestro autor:

"en vista de ello no debe extrañar que la organización profesional, doquiera que ha adquirido realidad, haya tenido por consecuencia que uno o más grupos pretendiesen imponerse a los restantes, lo que permite sospechar sin temeridad que en la aspiración reiterada recientemente en pro de una organización estamental late no tanto el anhelo de una participación orgánica y justa de todos los grupos profesionales en la elaboración de la voluntad del Estado, como la ambición hacia el poder sentida por algunos sectores interesados a quienes la Constitución democrática no ofrece, al parecer, probabilidades de éxito...Mientras los proletarios de las profesiones más diversas... se sientan unidos entre sí por una comunidad de intereses más efusiva que con los patronos capitalistas del mismo grupo profesional, y mientras ante esta realidad innegable se inclinen también los patronos capitalistas del mismo grupo profesional, y mientras ante esta realidad innegable se inclinen también los patronos a una solidaridad que supere las barreras profesionales, no podrán brotar las de las circunstancias

20. Ibíd., p. 64

21. Ibíd., p. 65

22. Ibíd.

23. Ibíd., p. 74

24. Ibíd., p. 77 
sociales una organización profesional capaz de acabar con la actual forma parlamentariodemocrática de Estado, si no es aproximándose a un régimen autocrático, y erigiendo, en definitiva, un poder dictatorial de una clase sobre las restantes". ${ }^{25}$

\section{Conclusión}

Tenía Hans Kelsen casi 40 años cuando se editó por primera vez Esencia y valor de la democracia. Si bien tuvo una larga vida (nació en 1881 y murió en 1974), no es fácil establecer que tan de "juventud" o de "inmadurez" sea el texto que hemos reseñado en este ensayo. La verdad, poco importa, pues su frescura y actualidad son lo más significativo para nosotros. Viene a cuento aquí una nota del escritor Javier Marías -la nota se titula "La perversión de los viejos"26 - en la cual cuestiona la suposición de que en la vejez las personas tienen más sabiduría; se descubrió - dice Marías - que la misma "bien estaba ya en cada persona antes de alcanzar la ancianidad, o no hacía acto de aparición con los años, así, como por ensalmo". ${ }^{27}$

De tal suerte que la presunción de que la obra un autor anciano es mejor que su obra cuando era un autor joven no tiene ningún fundamento. Kelsen -que no estaba precisamente joven cuando escribió Esencia y valor de la democracialo desmiente. Y, bien visto, quizás fueron sus energías de juventud las que le permitieron escribir un ensayo tan lúcido y claro en sus formulaciones; un ensayo que tiene como referencia la realidad, y no ideaciones ajenas a la misma.

Es natural que quienes vean como sus enemigos a los partidos políticos y a los parlamentos (o Asambleas Legislativas) -a los cuales pretenden reemplazar con gremiales empresariales o profesionales-, no se sientan cómodos con este escrito de Kelsen. Igualmente incómodos se habrán de sentir los "kelsenianos" que dicen ampararse en él (en otras obras suyas) para invalidar la primacía de los partidos y los parlamentos en el ejercicio democrático, pretendiendo hacer de otra instancia institucional (por ejemplo, el Poder Judicial o la Sala de lo Constitucional o el Tribunal Constitucional) el realizador del ideal democrático. Esa pretensión -siguiendo al Kelsen de Esencia y valor de la democracia- es absolutamente antidemocrática, lo mismo que lo es pretender reemplazar a los partidos políticos y los parlamentos por gremiales profesionales o empresariales, así estén conformadas por los individuos más talentosos y preparados técnicamente (o académicamente, si se quiere) de un país.

Si hay en otras obras de Kelsen posturas opuestas a las defendidas en Esencia y valor de la democracia, es bueno que los kelsenianos las expongan -siguiendo, si les parece el procedimiento, ensayado aquí (y que no es otra cosa que un ejercicio de análisis de los que se hacen -o hacían- en los últimos años de

25. Ibíd., pp. 78-80

26. Javier Marías, Tiempos ridículos. Madrid, Alfaguara, 2013, pp. 135-138

27. Ibíd., p. 135 
cualquier carrera humanista) y que sean los lectores críticos quienes ponderen su racionalidad y pertinencia para el momento actual. No se trata, por tanto, de si Kelsen lo dijo (o lo dijo cualquier otra figura intelectual), sino si lo dicho es relevante y razonable. Porque de que alguien sea una figura intelectual relevante no se sigue que siempre y en todo lugar diga (o escriba) cosas relevantes.

\section{Bibliografía}

R. del Águila, et al, La democracia en sus textos. Madrid, Alianza, 1998.

M. Gauchet, La democracia contra sí misma. Santa Fe, Homo Sapiens, 2002.

L. A. González, La democracia y sus exigencias. San Salvador, ISD, 2009.

D. Held, La democracia y el orden global. Barcelona, Paidós, 1977.

H. Kelsen, Esencia y valor de la democracia. Barcelona, Labor, 1977.

J. Marías, Tiempos ridículos. Madrid, Santillana, 2013.

A. Touraine, ¿Qué es la democracia? México, FCE, 2006. 